\title{
Occurrence of Soil-transmitted Helminths from Selected Dumpsites and Farmlands in Calabar, Nigeria
}

\author{
Edema Enogiomwan Imalele ${ }^{1^{*}}$, Effanga Emmanuel Offiong ${ }^{1}$, \\ Usang Anok Ukam ${ }^{1}$, Aramushu Willington Urimaneh ${ }^{1}$ \\ and Henshaw Victoria Utibe ${ }^{1}$ \\ ${ }^{1}$ Department of Zoology and Environmental Biology, University of Calabar, Calabar, P.M.B. 1115, \\ Cross River State, Nigeria.
}

Authors' contributions

This work was carried out in collaboration among all authors. Authors AWU and HVU were involved in sample collection. Authors UAU and EEI performed the parasitological analysis of the samples obtained from the field. Authors EEI and EEO analyzed and interpreted the data obtained from the study. All authors read and approved the final manuscript.

Article Information

DOI: $10.9734 / A R R B / 2021 / v 36 i 530371$ Editor(s):

(1) Prof. Tunira Bhadauria, Kanpur University, India. Reviewers:

(1) Aubin Armel Koumba, Research Institute in Tropical Ecology, Gabon. (2) Farah Haziqah Binti Meor Termizi, University Sains Malaysia, Malaysia. Complete Peer review History: http://www.sdiarticle4.com/review-history/68607

Original Research Article

Received 14 March 2021

Accepted 19 May 2021

Published 25 May 2021

ABSTRACT

Aims: The present study investigated the prevalence and intensity of soil-transmitted helminth contamination in dumpsite and farmland soils in Calabar, Cross River State, Nigeria.

Methodology: Soil samples were randomly collected from selected dumpsites and farmlands from July to December 2019. 200 soil samples (100 samples each from dumpsites and farmland) were collected. Soil samples were analysed using Zinc sulphate flotation technique whereas soil nematode extraction for hookworm and Strongyloides larvae was carried out using the modified Baermann technique.

Results: Of the 200 soil samples examined, 131 (65.5\%) were positive for ova/larvae of one or more parasites. Dumpsite soils were highly contaminated with ova/larvae of soil-transmitted helminths than farmland soils with a prevalence of $79 \%(n=79)$ and $52 \%(n=52)$ respectively $(P=.02)$. Farmlands had the highest mean intensity $(6.75 \pm 1.88)$ of contamination with ova/larvae of soil-transmitted helminths compared to dumpsite soils (1.68 \pm 0.14$)$. Ascaris lumbricoides recorded 
the highest occurrence (35.5\%) $(P=.003)$ in soil samples examined. A. lumbricoides (40\%) and Trichuris trichiura (6\%) contamination was higher in dumpsite soils, while Strongyloides stercoralis larvae (34\%) and hookworm (10\%) contamination was higher in farmland soils. Dumpsite soils recorded the highest number of parasites $(84 \%)$ in the wet season, while farmland soils recorded the highest number of parasites $(92 \%)$ in the dry season $(P=.11)$. Generally, parasitic ova/larvae were more prevalent in the dry season $(91 \%)$ than in the wet season $(73 \%)(P=.33)$. S. stercoralis $(33 \%)$ was more prevalent in the wet season followed while A. lumbricoides (43\%) recorded highest occurrence in the dry season.

Conclusion: This study revealed the potential health risk of contracting soil-transmitted helminth parasites in soils around farmlands and dumpsites in Calabar, Nigeria. It is therefore important that a combination of sanitation and health education be put in place for effective control of soiltransmitted helminths.

Keywords: Soil-transmitted helminthes; soil; dumpsite; farmland; soil contamination; Nigeria.

\section{INTRODUCTION}

Soil-transmitted helminths are found worldwide with a public health concern to both man and animals. Soil is a potential source of human diseases caused by numerous soil-transmitted helminth parasites [1]. These diseases include ascariasis, hookworm disease, trichuriasis, and strongyloidiasis, among others. Transmission of these diseases is enhanced by poor socioeconomic conditions, deficiencies in sanitary facilities, improper disposal of human faeces, insufficient supplies of potable water, poor personal hygiene, sub-standard housing and lack of education [2]. Children in developing countries are the most important vulnerable group to these infections since they usually play within the grounds [3].

Ogwurike, et al. [4] stated that humid warm temperature, shade and contamination of soil with organic decomposing matter as major factors that favour the development and spread of these parasites. These conditions are more common in areas where wastes are disposed indiscriminately and are not promptly evacuated to safe dump sites [5]. The organic wastes decompose polluting the environment and spread infective ova and larvae of helminths especially in areas where such organic wastes are used as manure on farmlands. In Nigeria, a large amount of both human and animal waste are discharged into the soil daily leading to the contamination of the soil with pathogenic organisms including soil-transmitted helminth eggs and larvae [6]. Previous studies have reported soil contaminated with soil-transmitted helminths in both rural and urban settings in Nigeria [7,8,9] with soil-transmitted helminths infections more prevalent in the South-West region [10].
Scavengers are known to visit dumpsites looking for scrapes, often doing so barefooted and with unprotected hands, thus exposing themselves to infection by soil-transmitted helminths. Also, farmers use untreated sewage for manure contaminating farm produce. Such traits are of serious public health concern especially pertaining to soil-transmitted helminth infections. Most often humans become infected by ingestion of the infective form of soil-transmitted helminths either from soil, raw fruit and vegetables, or dirty hands [11].

Despite the possible risk of acquiring soiltransmitted helminth infections from dumpsite and farmland soils, there appear to be a dearth of information on the possible parasites recovered from dumpsite and farmland soils in Calabar, Nigeria. Furthermore, a bulk of the investigations carried out on soil-transmitted helminths were based on faecal samples obtained from participants, while only a few were related to soil samples [12]. Hence the present study investigated the prevalence and intensity of soil-transmitted helminth contamination in dumpsite and farmland soils in Calabar metropolis, Nigeria.

\section{METHODOLOGY}

\subsection{Study Area}

The study was carried out in Calabar, the capital of Cross River state. It is located close to the coastal region of the Atlantic Ocean. Calabar metropolis lies between Latitude $04^{\circ} 15^{\prime}$ to $5^{\circ} 15^{\prime}$ North and Longitude $8^{\circ} 15^{\prime}$ to $8^{\circ} 25^{\prime}$ East. Calabar Metropolis is made up of two Local Government Areas (LGAs); Calabar-South LGA and Calabar Municipal LGA. In the North, the Municipal is bounded by Odukpani LGA, in the North-East by the Great-Kwa River (Fig. 1). Its 
Southern shores are bounded by Calabar River and Calabar South LGA. It has an area of $331,551 \mathrm{~km}^{2}$ [13]. There is an all year round rainfall of about $350 \mathrm{~mm}$. Peak precipitation occurs in July and September. Daily temperatures all through the year range between $22.4^{\circ} \mathrm{C}$ and $33.2^{\circ} \mathrm{C}$, and relative humidity is from $60 \%$ to $93 \%$. Calabar has a tropical climate [14].

\subsection{Sample Collection}

Soil samples were collected from dumpsites and farmlands. Four different dumpsite and farmland locations were randomly selected. A total of 25 soil samples each were collected from the randomly selected dumpsites and farmlands. A total of 200 soil samples (100 samples each from dumpsites and farmland) were collected between July and December 2019. Soil samples were collected in the morning (7am-11am) as recommended by Nwoke et al. [7]. Approximately $100 \mathrm{~g}$ of soil was randomly collected at a depth of $2 \mathrm{~cm}$ into the soil [8] using hand trowel sterilized by cleaning with $95 \%$ ethanol. Soil samples collected were stored properly in labelled screw capped specimen bottles and transported to Zoology and Environmental Biology Laboratory, of the University of Calabar and were analysed for the presence of human soil-transmitted helminths eggs or larvae using standard methods.

\subsection{Parasitological Analysis of Soil Samples}

\subsubsection{Zinc sulphate flotation technique}

Zinc sulphate flotation technique described by Ogbolu et al. [15] was used for examination of soil samples. Each soil sample was sieved to remove debris, coarse particles and other unwanted materials. About $20 \mathrm{~g}$ of the soil was mixed with $10 \mathrm{mls}$ of distilled water. The solution was strained into a test tube and centrifuged at $2500 \mathrm{rpm}$ for 3 minutes. The supernatant was decanted and the sediment was mixed with $10 \mathrm{ml}$ zinc sulphate solution of $33 \%$ weight per volume (Specific gravity 1.20). The zinc sulphate solution was added to the brim of the test tube. The preparation was allowed to stand for few minutes with a cover slip placed on the tube to collect floating ova. The cover slip was carefully removed and placed faced down on a clean glass slide for examination under the $\times 10$ and $\times 40$ objective lens.

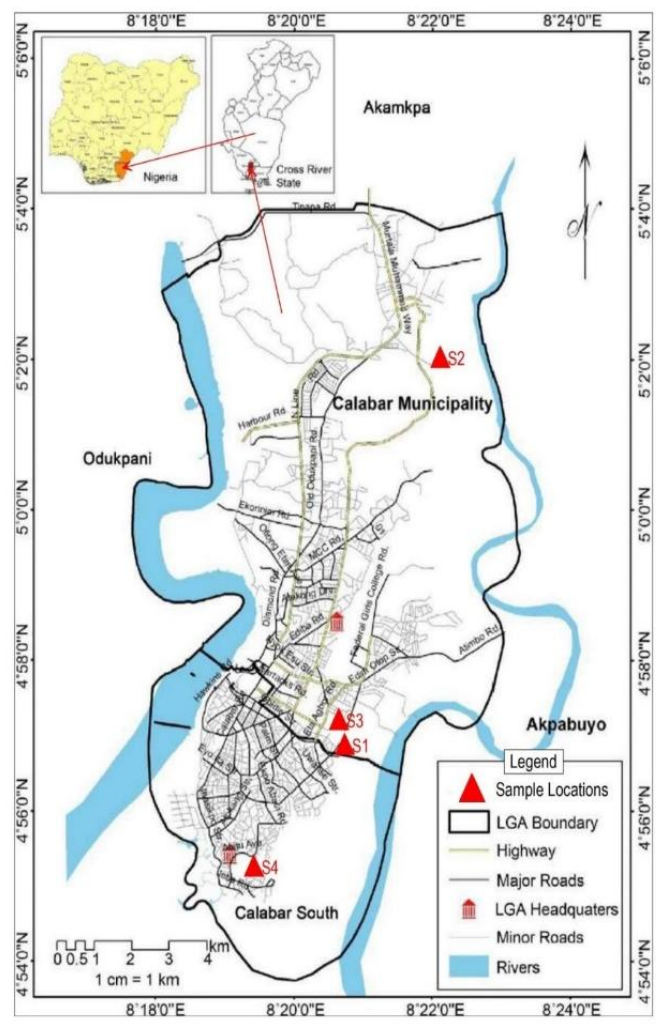

Fig. 1. Map of Calabar Metropolis showing the sampling sites 


\subsubsection{Modified Baermann technique}

Soil nematode extraction for hookworm and Strongyloides larvae was carried out using the Modified Baermann technique as described by Collender et al. [16]. The setup comprises of a modified funnel with a short piece of rubber tubing attached to the stem and a clamp closure. The funnel was supported uprightly and filled with water. Approximately $20 \mathrm{~g}$ of soil was placed on top of a filter paper on top of a wire gauze. The enclosed soil sample was placed in the Baermann funnel (filled with distilled water). The larvae migrated through the filter paper and into the water in the funnel. The larvae settled at the bottom of the funnel by gravity and were collected after 48-72 h. The suspension was viewed under the microscope for the presence of nematodes. Parasites were identified with the aid of standard guidelines provided by Chiodini et al. [17]. Any egg/larvae found were counted and recorded as described by [1]. Parasite intensity (total mean egg/larvae) was estimated per gram of soil samples using method described by Olufotebi et al. [18].

\subsection{Statistical Analysis}

Data were analysed using the Statistical Package for Social Science (SPSS) version 22 (SPSS Inc., Chicago, IL, USA). Figures were designed using Graphpad Prism, version 5.0. The Chi square $\left(x^{2}\right)$ test was used for the comparison of prevalence of soil transmitted helminth contamination between the variables. One-way Analysis of Variance (ANOVA) was used to compare the mean intensities of soiltransmitted helminths contamination in the different sampling sites. Significant levels were set at $P=.05$.

\section{RESULTS}

Of the 200 soil samples collected from various locations in Calabar, 131 (65.5\%) were positive for ova/larvae of one or more parasites. Dumpsite soils (79\%) recorded high contamination with ova/larvae of soil-transmitted helminths as compared to the farmland soils $(52 \%)(P=.02)$ (Table 1). Generally, farmlands had the highest mean intensity of parasitic contamination $(6.75 \pm 1.88)$ compared to dumpsite soils $(1.68 \pm 0.14)$ (Table 1$)$. This difference was however not statistically significant $(P=.096)$.

The distribution of parasites in the different soil samples varied significantly $(P=0.003)$. $A$. lumbricoides recorded the highest prevalence $(35.5 \%)$, followed by $S$. stercoralis larvae $(32.5 \%)$, hookworm $(9.5 \%)$, T. trichiura $(3.5 \%)$ and Taenia sp. (1\%) $(P=.003)$ (Table 2). A. lumbricoides $(40 \%)$ and $T$. trichiura $(6 \%)$ contamination was higher in dumpsite soils compared to farmland soils, while $S$. stercoralis larvae (34\%) and hookworm (10\%) contamination was higher in farmland soils (Table 2).

Table 1. Prevalence and mean egg density of Soil-transmitted helminths in dumpsite and farmland soils in Calabar

\begin{tabular}{llll}
\hline Examined sites & Number of samples & Samples with eggs (\%) & $\begin{array}{l}\text { Mean egg density per } \\
\text { positive sample (20g) } \\
\text { Mean } \pm \text { Standard error }\end{array}$ \\
\hline Dumpsites & $n=100$ & & $1.68 \pm 0.14$ \\
Site 1 & 25 & $79(79)$ & $1.70 \pm 0.14$ \\
Site 2 & 25 & $20(80)$ & $2.20 \pm 0.23$ \\
Site 3 & 25 & $20(80)$ & $1.46 \pm 0.09$ \\
Site 4 & 25 & $21(84)$ & $1.36 \pm 0.10$ \\
\hline Farmlands & $n=100$ & $18(72)$ & $6.75 \pm 1.88$ \\
Farm 1 & 25 & $52(52)$ & $11.25 \pm 2.25$ \\
Farm 2 & 25 & $10(40)$ & $12.25 \pm 3.77$ \\
Farm 3 & 25 & $16(64)$ & $2.50 \pm 1.50$ \\
Farm 4 & 25 & $15(60)$ & $1.00 \pm 0.00$ \\
Total & $\mathrm{n}=200$ & $11(44)$ & $4.23 \pm 1.01$ \\
P-value & & $131(65.5)$ & 0.096 \\
\hline
\end{tabular}


The distribution of parasites in the wet season revealed that dumpsite soils recorded the highest number of parasites (84\%) while in the dry season, farmland soil recorded the highest prevalence of parasites (92\%) (Fig. 2). This difference was however not statistically significant $(P=0.11)$. S. stercoralis larvae $(33 \%)$ was more prevalent in the wet season followed by ova of $A$. lumbricoides (28\%) and hookworm $(10 \%)$. However, in the dry season, ova of $A$. lumbricoides $(43 \%)$ was more prevalent followed by S. stercoralis larvae (32\%) and hookworm ova $(9 \%)$. Ova of Taenia sp. was only recovered in the dry season. Overall, parasites were more prevalent in the dry season (91\%) than in the wet season (73\%) (Fig. 3). Parasite distribution according to seasons showed no significant variation $(P=.33)$.

\section{DISCUSSION}

The presence of soil-transmitted helminth eggs and larvae in soil obtained from dumpsites and farmlands is of great epidemiological significance. Specific occupations such as engagement in agricultural pursuits and behaviours (scavenging/picking scraps from dumpsites) influence the prevalence and intensity of soil-transmitted helminth infections $70.8 \%[7]$.

Table 2. Species specific prevalence of helminths in dumpsites and farmlands soil samples in Calabar

\begin{tabular}{llllllll}
\hline Examined & $\begin{array}{l}\text { Number } \\
\text { sites }\end{array}$ & examined & \multicolumn{6}{c}{ Number positive (\%) } & $\begin{array}{l}\boldsymbol{A} \text {. } \\
\text { lumbricoides }\end{array}$ & $\begin{array}{l}\text { S. } \\
\text { stercoralis } \\
\text { larvae }\end{array}$ & Hookworm & $\begin{array}{l}\boldsymbol{T} \text { T. } \\
\text { trichiura }\end{array}$ & $\begin{array}{l}\text { Taenia } \\
\text { sp. }\end{array}$ & \\
value & & & & \\
\hline Dumpsites & 100 & $40(40)$ & $31(31)$ & $9(9)$ & $6(6)$ & $1(1)$ & 0.003 \\
Site 1 & 25 & $8(32)$ & $12(48)$ & $2(8)$ & - & - & \\
Site 2 & 25 & $10(40)$ & $2(8)$ & $7(28)$ & $3(12)$ & $1(4)$ & \\
Site 3 & 25 & $12(48)$ & $9(36)$ & - & $3(12)$ & - & \\
Site 4 & 25 & $10(40)$ & $8(32)$ & - & - & - & \\
Farmlands & 100 & $31(31)$ & $34(34)$ & $10(10)$ & $1(1)$ & $1(1)$ & \\
Farm 1 & 25 & $3(12)$ & $5(20)$ & $1(4)$ & $1(4)$ & $1(4)$ & \\
Farm 2 & 25 & $8(32)$ & $10(40)$ & $4(16)$ & - & - & \\
Farm 3 & 25 & $10(40)$ & $12(48)$ & $1(4)$ & - & - & \\
Farm 4 & 25 & $10(40)$ & $7(28)$ & $4(16)$ & - & - & \\
Total & 200 & $71(35.5)$ & $65(32.5)$ & $19(9.5)$ & $7(3.5)$ & $2(1.0)$ & \\
\hline
\end{tabular}

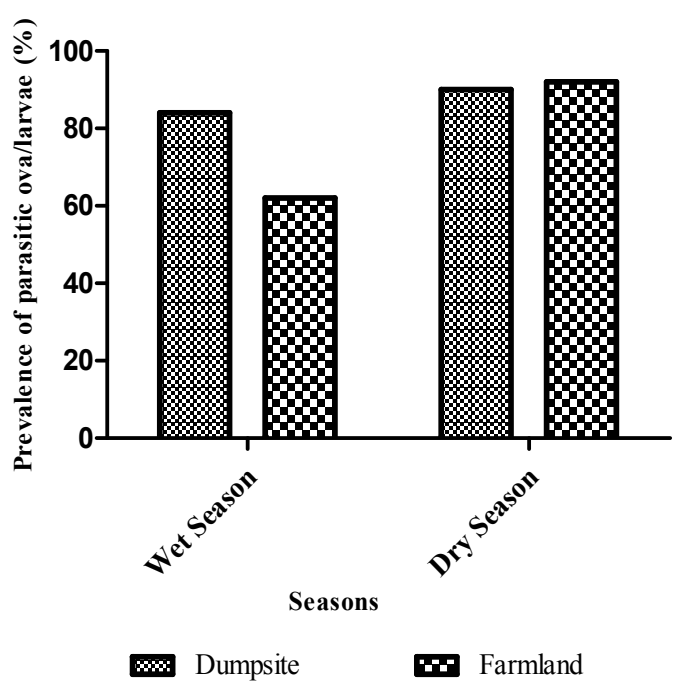

Fig. 2. Overall distribution of soil-transmitted helminths in dumpsite and farmland soils according to seasons. Wet season (dumpsite, $n=42$; farmland, $n=31$ ) and Dry season (dumpsite, $n=45 ;$ farmland, $n=46$ ) 


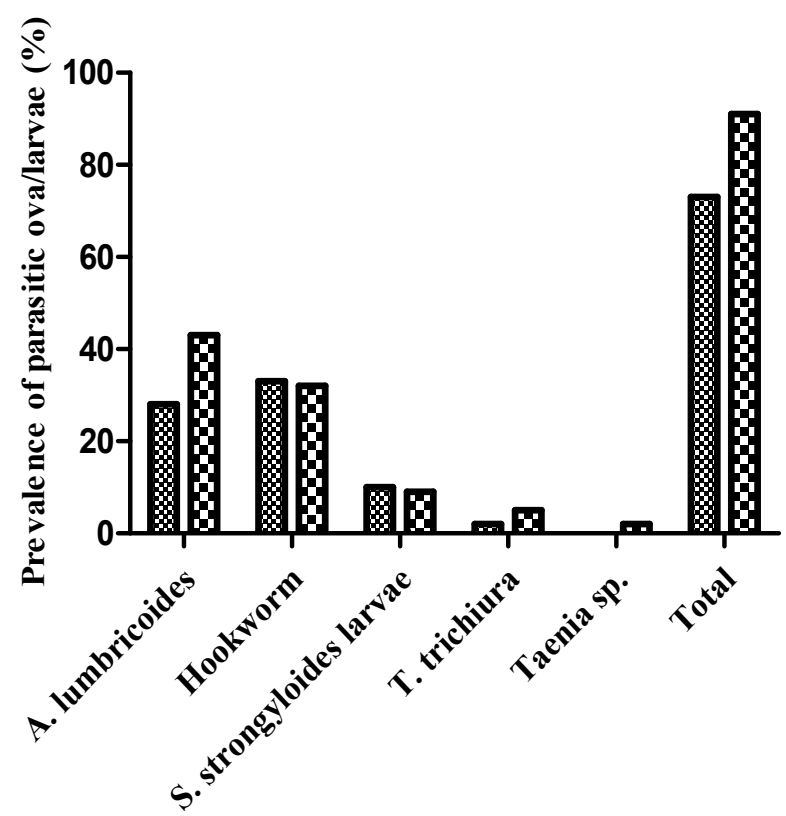

Parasite types

W Wet Season $\mathbf{m}$ Dry Season

\section{Fig. 3. Seasonal distribution of soil-transmitted helminths in dumpsite and farmland soil} samples

The prevalence of soil-transmitted helminths recorded in this study is similar to $62 \%$ reported previously in Ibadan by Olufotebi, et al. [18]. This is however lower than those obtained $(11.5 \%$, $54.9 \%$ and $30.7 \%$ ) by Debalke et al. [19], Oyebamiji et al. [9] and Nwoke et al. [7] in Ethiopia, Oyo and Ebonyi States, respectively. This variation could be as a result of differences in environmental and climatic factors, awareness and perception among citizens. Hygiene and sanitation policies also differ in different regions [18]. Although these were not investigated during the study, temperature, $\mathrm{P}^{\mathrm{H}}$ and organic carbon content have been demonstrated to positively influence the abundance of geohelminths in soil Ovutor et al. [20]. Inadequate knowledge on the prevention, control and transmission of soiltransmitted helminths have been shown to be a significant risk factor in soil-transmitted helminth transmission [9].

Dumpsite soils $(79 \%)$ were significantly more contaminated with ova/larvae of soil-transmitted helminths than farmland soils $(52 \%)$ and a similar observation was recorded by Hassan et al. [8] and Oyebamiji et al. [9] in Oyo State, Nigeria. Oyebamiji et al. [9] stated that such a situation provides a continuous/reserved source of infection in communities where such dumpsites are located. Open defecation or disposal of sewage in dumpsites increase the risk of soiltransmitted helminth infections.

A. lumbricoides recorded the highest prevalence $(35.5 \%)$, followed by $S$. stercoralis larvae (32.5\%), hookworm (9.5\%), T. trichiura (3.5\%) and Taenia sp. (1\%). This range of parasitic contamination of soil have also been reported by Paller and Babia-Abion [21] in Philippines. A higher prevalence of $A$. lumbricoides compared to other parasites found have also been reported in other studies $[7,22,21]$. The high prevalence of A. lumbricoides could be due to the high resistant nature of the ova which can embryonate under adverse environmental conditions and also survive in the presence of chemicals that are known to be lethal to other parasites' eggs [22].

Overall, parasites were more prevalent in the dry season (91\%) than in the wet season (73\%). Similar result was reported by Nwoke et al. [7] who suggested that it could be due to the suitable environmental and climatic conditions. Furthermore, Owhoeli et al. [23] also stated that parasites may be more prevalent in soil during 
the dry season due to moderate temperature and high organic content in the soil during this period. As stated by Oyebamiji et al. [22] and Delaluna et al. [24] $A$. lumbricoides produce high resistant eggs which can embryonate under adverse environmental conditions. This is evident in this study as ova of $A$. lumbricoides (43\%) was more prevalent in the dry season, followed by $S$. stercoralis larvae (32\%) and hookworm ova (9\%) in which the results corroborate the findings of Nwoke et al. [7].

While $A$. lumbricoides was more prevalent during the dry season, $S$. stercoralis was more prevalent during the wet season. This is similar to the findings reported by Isaac et al. [25] in Edo State, Nigeria. It was stated that larvae of $S$. stercoralis thrive under optimal conditions which include soil temperatures between 20 to $28^{\circ} \mathrm{C}$ and high moisture, which is likely the case during the wet seasons in most parts of Southern Nigeria.

\section{CONCLUSION}

This study revealed the potential health risk of contracting soil-transmitted helminth parasites in soils around farmlands and dumpsites in Calabar, Nigeria. This poses a risk, particular to scavengers and environmental officers who visit these dumpsites regularly. Also, farmers and the community at large are at risk as farm produce from these farmlands could be contaminated with soil-transmitted helminth eggs or larvae. It is therefore important that a combination of sanitation and health education be put in place for effective control of soil-transmitted helminths.

This study is limited by the use of old methods to examine helminth eggs which could lead to the under-reporting of contaminated soils. Using more sensitive and specific diagnostic approaches such as Polymerase Chain Reaction (PCR) for future studies is recommended.

\section{CONSENT AND ETHICAL APPROVAL}

The purpose of the study was explained to the communities' head who in turn enlightened the farmers in the study area. Also, permission to carry out the study was obtained from the communities' head in areas where the dumpsites were located. Informed consent was obtained from farmers whose farms were used in this study.

\section{ACKNOWLEDGEMENTS}

We acknowledge the staff of the Department of Zoology and Environmental Biology, University of Calabar, for their assistance during the course of this study.

\section{COMPETING INTERESTS}

Authors have declared that no competing interests exist.

\section{REFERENCES}

1. Paller VGV, Chavez ERC. Toxocara (Nematoda: Ascaridida) and other soiltransmitted helminth eggs contaminating soils in selected urban and rural areas in the Philippines. The Science World Journal. 2014;386:23-26.

2. Agbom MC, Odikamnoro OO, Omowaye OS. Soil helminthiasis on farmland in Ebonyi State, Nigeria. Unique Research Journal of Agricultural Sciences. 2013; 1(5):70-75.

3. Patel SS, Kazura JW, Hotez PJ, King, CH, Blanton R. Helminthic Diseases. In: Behrman RE. Kliegman RM, Jenson HB (eds). Nelson Textbook of Paediatrics 17th Ed: International Edition, Philadelphia, Saunders. 2004;1155-1174.

4. Ogwurike BA, Ajai JA, Ajayi OO. A comparative study of helminthiasis among pupils of private and public primary schools in Jos North Local Government Area of Plateau State, Nigeria. Nigeria Annals of Natural Science. 2010;10(1): 28-41.

5. Ikpeama CA, Ogomaka Al, Ifeanyi OC. The Impact of Refuse Disposal Dumpsite on the Spread of Intestinal Helminthiasis in Owerri Metropolis, Imo State, South Eastern Nigeria. International Journal of Clinical Chemistry and Laboratory Medicine. 2016;2:13-18.

6. Uhuo CA, Nwanchor $\mathrm{K}$, Umene DA. Helminth parasites of fruits and vegetables planted in crop and landscape management Garden College of Agricultural Sciences, Ebonyi State University, Abakaliki: Implication for Public Health. Journal of Biology, Agriculture and Healthcare. 2013;3(9):9-11.

7. Nwoke EU, Ibiam GA, Odikamnoro OO, Umah OV, Ariom OT, Orji I. Examination of 
soil samples for the incidence of geohelminth parasites in Ebonyi Northcentral area of Ebonyi State, South-East of Nigeria. Annals of Applied Science Research. 2013;5:41-48.

8. Hassan AA, Oyebamiji DA, Idowu OF. Spatial patterns of soil transmitted helminths in soil environment around Ibadan, an endemic area in south-west Nigeria. Nigerian Journal of Parasitology. 2017;38:179-184.

DOI: 10.4314/njpar.v38i2.9

9. Oyebamiji DA, Ebisike AN, Egede JO, Hassan AA. Knowledge, attitude and practice with respect to soil contamination by soil-transmitted helminths in Ibadan, Southwestern Nigeria. Parasite Epidemiology and Control. 2018;3:e00075.

DOI: 10.1016/j.parepi.2018.e00075

10. Karshima NS, Maikai B, Kwaga PKJ. Helminths of veterinary and zoonotic importance in Nigerian ruminants: a 46year meta-analysis $(1970-2016)$ of their prevalence and distribution. Infectious Disease and Poverty. 2018;7:52.

DOI: $10.1186 / s 40249-018-0438-z$

11. Blaszkowska J, Kurnatowski P, Damiecka $P$. Contamination of the soil by eggs of geohelminths in rural areas of Lodz district (Poland). Helminthologia.2011;48(2):67-76.

12. Hassan AA, Oyebamiji DA. Intensity of soil transmitted helminths in relation to soil profile in selected public schools in Ibadan metropolis. Biometrics and Statistics International Journal. 2018;7(5):413-417.

DOI: 10.15406/bbij.2018.07.00239

13. Usip LPE, Afia OE, Etok MI. Prevalence of Geohelminths on Selected Fruits and Vegetable sold in Calabar, cross River state, Nigeria. Journal of Agriculture, Food and Vegetable. 2017; 13(3):35-39.

14. Ottong JG, Ering SO, Akpan, FU. The population situation in cross river state of Nigeria and its implication for socioeconomic development: Observations from the 1991 and 2006 censuses. J. Emerg. Trends Educ. Res. Policy Stud. 2020;1:3642.

15. Ogbolu DO, Terry Alli OA, Amoo Olaosun AOJ, llozavbie II GW, Olusoga-Ogbolu FF. High-level parasitic contamination of soil sampled in Ibadan metropolis. Afr. J. Med. Sci. 2011; 40:85-87.
16. Collender PA, Kirby AE, Addiss DG, Matthew CF, Justin VR. Methods for quantification of soil-transmitted helminths in environmental media: current techniques and recent advances. Trends in Parasitology. 2015;31:12.

17. Chiodini PL, Moody AH, Menser DW. Atlas of Medical Helminthology and Protozoology. $4^{\text {th }}$ ed.; 2001.

18. Olufotebi I, Odeniran PO, Ademola IO. Prevalence of soil-transmitted helminths' ova in soil in Ibadan, Oyo State, Nigeria. Nigerian Journal of Parasitology. 2019; 40(2):186-192.

19. Debalke S, Worku A, Jahur N, Mekonnen Z. Soil transmitted helminths and associated factors among schoolchildren in government and private primary school in Jimma Town, Southwest Ethiopia. Acta Parasitologica Globalis. 2012;6(1):29-35.

20. Ovutor O, Imafidor H, Grace D, Awi-waadu B. Assessment of physico-chemical parameters of soils in fallowing farmlands and pit toilet environments as it affects the abundance of geohelminths in Emuhua Local Government Area, Rivers State, Nigeria. Annual Research and Review in Biology. 2017;14(3):1-10.

21. Paller VGV, Babia-Abion S. Soiltransmitted helminth (STH) eggs contaminating soils in selected organic and conventional farms in the Philippines. Parasite Epidemiology and Control. 2019; 7:e00119.

22. Oyebamiji DA, Olabode I, Hassan AA. Risk of exposure to soil-transmitted helminths in the zoological garden of Southwestern Nigeria. Asian Journal of Epidemiology. 2019;12:17-24.

23. Owhoeli O, Imafidon H, Awi-waadu GDB. Assessment of physico-chemical parameters of soils in fallowing farmlands and pit toilet environments as it affects the abundance of geohelminthes in Emohua Local Government Area, Rivers State. Nigeria. Annual Research \& Review in Biology. 2017;14(3):1-10.

24. Delaluna JOC, Flores MJC, Belizario Jr. VY, Janairo JIB, Derick EP, Sumalapao DEP. Soil-transmitted helminth egg contamination from soil of indigenous communities in selected barangays in Tigaon, Camarines Sur, Philippines. Asian Pac. J. Trop. Med. 2020;13(9):409-414. 
25. Isaac C, Turay PN, Inegbenosun $\mathrm{CU}$, primary school playgrounds in Edo State, Ezekiel SA, Adamu HO, Ohiolei JA. Southern Nigeria. Helminthologia. 2019; Prevalence of soil-transmitted helminths in 56(4):282-295.

(c) 2021 Imalele et al.; This is an Open Access article distributed under the terms of the Creative Commons Attribution License (http://creativecommons.org/licenses/by/4.0), which permits unrestricted use, distribution, and reproduction in any medium, provided the original work is properly cited.

Peer-review history:

The peer review history for this paper can be accessed here:

http://www.sdiarticle4.com/review-history/68607 